\title{
Aluminum Oxide Nanoparticles for Highly Efficient Asphaltene Separation from Crude Oil Using Ceramic Membrane Technology
}

\author{
Mashallah Rezakazemi ${ }^{1,}$, , Sahar Mirzaei ${ }^{2,3}$, Morteza Asghari ${ }^{3}$ and Javad Ivakpour ${ }^{4}$ \\ ${ }^{1}$ Department of Chemical Engineering, Shahrood University of Technology, Shahrood - Iran \\ 2 Separation Processes Research Group (SPRG), Department of Engineering, University of Kashan, Kashan - Iran \\ 3 Energy Research Institute, University of Kashan, Ghotb-e-Ravandi Ave., Kashan - Iran \\ ${ }^{4}$ Upgrading and Optimization Technologies Group, Petroleum Refining Division, Research Institute of Petroleum Industry, \\ 14665-1998 Tehran - Iran \\ e-mail: mashalah.rezakazemi@gmail.com \\ *Corresponding author
}

\begin{abstract}
The effects of aluminum oxide nanoparticles on the removal of asphaltenes from an Iranian crude oil (Soroush) using a ceramic membrane with pore size of $0.2 \mu \mathrm{m}$ were investigated. In order to achieve superior asphaltene separation by ultrafiltration, it is essential to make some changes for destabilizing asphaltene in crude oil. The asphaltene destabilization was done using crude oil contact with an acid containing dissolved metal ions. Metal oxide nanoparticles adsorbed asphaltene molecules and increased their molecular size. The nanoparticle of aluminum oxide was applied to alter precipitation and peptization properties of asphaltenes. Dynamic Light Scattering (DLS) was used to measurement of the asphaltene molecular size dissolved in toluene. Raman spectroscopy and the Tuinstra equation were used to determine the aromatic sheet diameter $\left(\mathrm{L}_{\mathrm{a}}\right)$ via the integrated intensities of the G and D1 modes. This revealed that the asphaltene particles react with nano aluminum oxide and the average molecular size of asphaltene was raised from 512.754 to $2949.557 \mathrm{~nm}$ and $\mathrm{L}_{\mathrm{a}}$ from 5.482 to 13.787. The obtained results showed that using nano aluminum oxides, asphaltene separation increased from 60-85wt\% to 90-97wt\% based on the asphaltene content of crude oil.
\end{abstract}

\section{INTRODUCTION}

Natural bitumen and heavy-oil as alternative oils are commonly identified by their density, viscosity, heteroatom and asphaltenes loading, $\mathrm{H} / \mathrm{C}$ ratio, and carbon residues. Different type of asphaltenes (according to polarity of oil and also interaction with other components in the oil) can be found in petroleum both in soluble form and in micelle and/ or steric-colloid forms. In overall, asphaltenes can be found like a molecular aggregate of petroleum which is soluble in benzene and xylene but cannot be dissolved in light hydrocarbon solvents like $\mathrm{C}_{5}$ to $\mathrm{C}_{8}$. Asphaltene typically is a combination of polar aromatic and naphthalenic molecules, containing nitrogen, sulfur and oxygen atmos. One of the significant issues that the oil industries are concerned is the precipitation of asphaltenes. The precipitation of asphaltenes makes various issues such as the blockage of crude oil extraction and the transport pipes and also the pollution of ecosystems. In addition, precipitated asphaltene increases the viscosity of crude oils, negatively impacting production (Ashtari et al., 2016a; Ashtari et al., 2016b; Goual et al., 2011; Kaminski et al., 2000).

Investigation of solving asphaltene precipitation and deposition problems can be categorized into four groups (Carlos da Silva Ramos et al., 2001; Mousavi-Dehghani et al., 2004; Vazquez and Mansoori, 2000): (a) the 
development of theoretical models; (b) the interfacial and colloidal performance of asphaltene in crude oils and their corresponding modeling systems; (c) the determination of chemical additives for the inhibition of asphaltene precipitation;(d) separating of asphaltene using additives, hydrocyclones and membranes.

Membrane separation has gained great popularity over the last 30 years and is going to be a promising technology (Baheri et al., 2015; Farno et al., 2014; Rezakazemi et al., 2017a; Rezakazemi et al., 2014; Rezakazemi et al., 2017b; Rezakazemi et al., 2017c; Rezakazemi et al., 2015a; Rezakazemi et al., 2015b, 2016; Shahverdi et al., 2013). The membrane based separation processes have numerous benefits such as stable effluent quality and small area requirement (Rezakazemi et al., 2013c; Rezakazemi and Mohammadi, 2013; Rostamizadeh et al., 2013). Moreover, no chemicals addition is required. Between membranes units, Ultrafiltration (UF) and Microfiltration (MF) are extensively used for separation purposes in the petroleum industry. Typically, polymeric membranes are employed and solvents are added to crude oil to reduce its viscosity (Rezakazemi et al., 2013b; Shirazian et al., 2012b; Shirazian et al., 2012c; Shirazian et al., 2012d). Solvent recovery following extraction, phase separation and metal removal are some examples of membrane separation in the petroleum industry. However, polymeric membranes cannot be used at high temperature and are not chemically stable in presence of heavy oil (Rezakazemi et al., 2012a, b; Rezakazemi et al., 2012c; Shirazian et al., 2012a). By contrast, the thermal and chemical stability of ceramic membranes makes it possible to apply UF processes at higher temperature to reduce viscosity of heavy hydrocarbon oils (Fasihi et al., 2012; Hashemi et al., 2012; Marjani et al., 2011; Marjani et al., 2012; Rezakazemi et al., 2011a; Rezakazemi et al., 2011b; Rezakazemi et al., 2011c).

Many studies have been reported on the UF of diluted waste oils, residua and bitumens using ceramic membranes. The goal of UF processes is to reduce the density and viscosity of the heavy oil and also remove some components like asphaltene. In previous work (Ashtari et al., 2012), asphaltenes removal from three kinds of Iranian crude oils with diverse asphaltene loadings were investigated using ceramic monolith membranes with 0.05 and $0.20 \mu \mathrm{m}$ pore sizes. The experiments were conducted at a temperature of $120^{\circ} \mathrm{C}$ and a differential pressure of $200 \mathrm{kPa}$ in a batch filtration unit. The asphaltene rejection and permeate flux were investigated in terms of time. The decline in the permeate flux and increase in the asphaltene rejection have been reported as a result of fouling the membrane. The permeate flux did not show a robust relation with pore size and this demonstrated that fouling of the ceramic membrane was according to the formation of the gel layer.
It is believed that the interfacial activity of asphaltene is a result of the existence of functional groups in the asphaltene. Asphaltene, due to different functional groups such as ether, hydroxyl, ester, carboxylic, ketone, amine, aldehyde, and amide, forms a surface charge at the interface. These particles can aggregate at a certain temperature, pressure, concentration, and presence of some additives (Abdrabo and Husein, 2012; Abu Tarboush and Husein, 2012). The larger asphaltene can be removed easily by UF. Several attempts have been made to show important metal-hydrocarbon interactions, especially between sites contain $\mathrm{N}$ and $\mathrm{S}$ atoms in the asphaltene molecule. Therefore, asphaltenes interact strongly with metal ions which can change their properties related to precipitation and peptization tendency (Kaminski et al., 2000).

Furthermore, potential applications of nanotechnology have been studied in heavy oil recovery and upgrading which currently focused on nanoparticles. Interest on the application of nanoparticles in heavy oil recovery and upgrading results from their superior numerous factors, such as providing exceptionally high surface area/volume ratios and functionalizable surface areas. Also, nanoparticles are highly mobile in porous media because they are much smaller than the relevant pore spaces, leading to effective transport (Nassar, 2010).

In this work, separation of asphaltene from an Iranian crude oil (Soroush) using a ceramic membrane with the pore size of $0.2 \mu \mathrm{m}$ and the effects of adding $\gamma$-alumina nanoparticles on increasing the molecular size of asphaltene and its separation by membrane were investigated. Raman spectrometry was employed as a method to characterize the average molecular dimension of asphaltene and DLS used to study the stages of size molecular alteration of the asphaltene dissolved in toluene. Iranian crude oils samples from the Khark Island field were used for testing this technique. In this paper, for the first time, the effects of aluminum oxide nanoparticles on the removal of asphaltenes from an Iranian crude oil using ceramic membrane were investigated. Aluminum oxide nanoparticle was applied to alter precipitation and peptization properties of asphaltenes. The asphaltene destabilization was done using crude oil contact with an acid containing dissolved metal ions.

\section{EXPERIMENTAL}

\subsection{Materials and Apparatus}

The Iranian crude oil sample (Soroush) was supplied from south reservoir Iranian petroleum field, Khark Island which is unstable with precipitation problem. The physical properties and metal contents of Soroush crude oil are demonstrated in Table 1 . Commercially available aluminum oxide, $\gamma-\mathrm{Al}_{2} \mathrm{O}_{3}$, nanoparticles (TECNAN) were used. The reported particle 


\section{Nitrogen Blanketing}

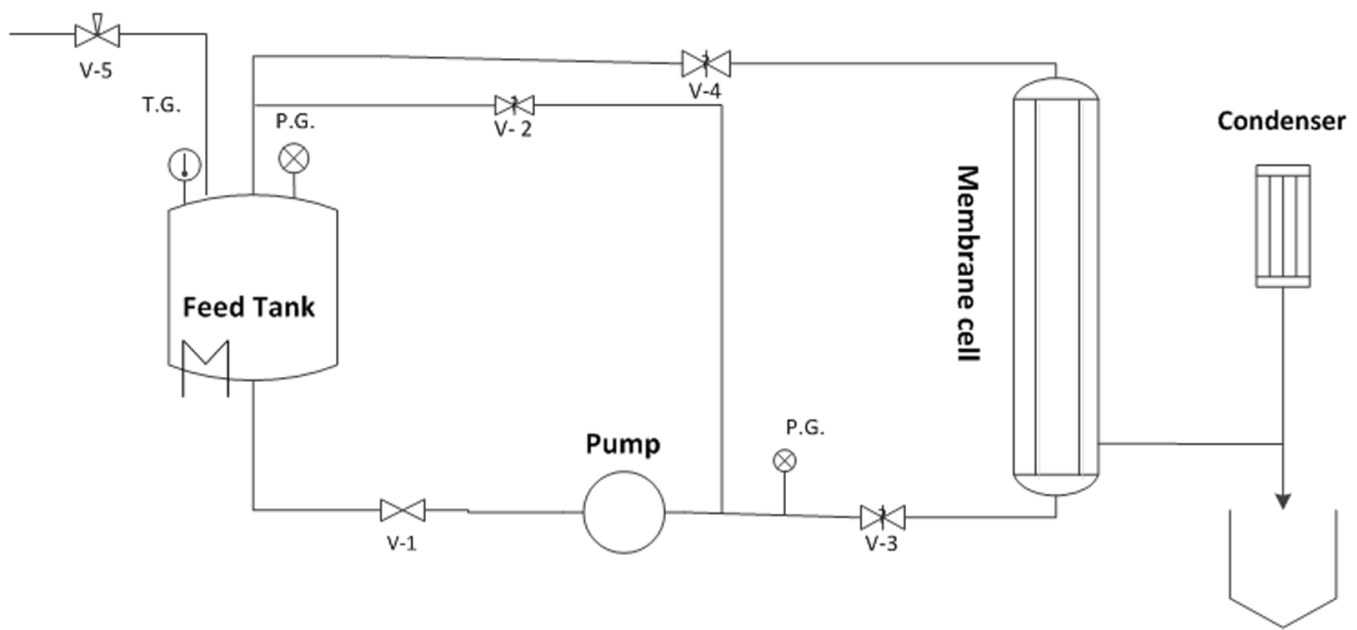

Permeate Vessel

Figure 1

Schematic of experimental setup.

TABLE 1

Physical properties of Soroush oil.

\begin{tabular}{l|l|l|l|l|l|l|l|l|l}
\hline Crude oil & $\begin{array}{l}\text { Asphaltene } \\
\text { content } \\
(\mathrm{wt} . \%)\end{array}$ & $\begin{array}{l}\text { Density } \\
\left(\mathrm{g} / \mathrm{cm}^{3}\right)\end{array}$ & $\begin{array}{l}\text { Viscosity at } 10^{\circ} \mathrm{C} \\
(\mathrm{cP})\end{array}$ & $\begin{array}{l}\text { Viscosity at } 20^{\circ} \mathrm{C} \\
(\mathrm{cP})\end{array}$ & $\begin{array}{l}\text { Viscosity at } 40^{\circ} \mathrm{C} \\
(\mathrm{cP})\end{array}$ & $\begin{array}{l}\text { Nickel } \\
(\mathrm{ppm})\end{array}$ & $\begin{array}{l}\text { Vanadium } \\
(\mathrm{ppm})\end{array}$ & $\begin{array}{l}\text { Iron } \\
(\mathrm{ppm})\end{array}$ & $\begin{array}{l}\text { Sodium } \\
(\mathrm{ppm})\end{array}$ \\
\hline Soroush oil & 11.82 & 0.9417 & 2603 & 1222 & 265 & 36 & 105 & 2 & 13 \\
\hline
\end{tabular}

size, purity, and specific surface area are $<30 \mathrm{~nm}, 99.99 \%$ and $90-160 \mathrm{~m}^{2} / \mathrm{g}$, respectively. The nanoparticles were used without further purifications. Merck toluene and n-heptane (All solvents were analytical reagent grade and used as received) were used for rinsing set up and determining amounts of asphaltene in each permeate of membrane output according to the most common and widely used method described in IP143/01 or D 6560-00 (ASTM, 2000). The procedure, defines asphaltene as a precipitated fraction of crude oil fluid formed by the incorporation of the extra ratio of n-heptane, therefore producing amorphous particles soluble in toluene. A schematic description of the experimental setup used in the present study is shown in Figure 1.

The crude oil from a feed tank enters the recycle loop using the feed pump by passing through the membrane cell. In membrane cell, 19-channels ceramic monolith membrane (length, $1016 \mathrm{~mm}$; outside diameter, $30.32 \mathrm{~mm}$; and inside diameter of each channel, $3.5 \mathrm{~mm}$, cross-section area, $0.212 \mathrm{~m}^{2}$ ) is secured in the housing by two different Orings. The feed was passed through the tube side, and permeate was collected from the shell side. A reflux condenser was used to prevent light end evaporation.

\subsection{Experimental Procedures}

The Taguchi method can reduce the overall experimental time and costs. Therefore, this systematic method was adopted to optimize the operating parameters (Rezakazemi et al., 2013a). Using the orthogonal array specially designed for the Taguchi method, the optimum experimental conditions such as various quantities of aluminum oxide nanoparticles $(0.005,0.01$, and $0.05 \mathrm{wt} . \%)$, membrane pore sizes $(0.05,0.2$ and $0.5 \mu \mathrm{m})$ can be easily determined. These results showed that the optimum condition for separating asphaltene by the membrane is $(0.05 \mathrm{wt} . \%$ aluminum oxide nanoparticles and $0.2 \mu$ pore size).

$5 \mathrm{~L}$ of Soroush oil with 0.05 wt.\% of aluminum oxide nanoparticles is charged to the feed vessel and heaters are turned on. At the beginning of the experimental run, in order to reduce the viscosity of crude oil, heavy oil is pre-heated in the feed tank. Then, the feed pump is started. The feed initially is routed in the loop line. It took approximately four hours to reach a stable temperature of feed tank. After that, the V-2 valve is closed and V-3 and V-4 valves are opened in order to allow the fluid to circulate. Lighter smaller size particles separate from the main feed by passing through the 


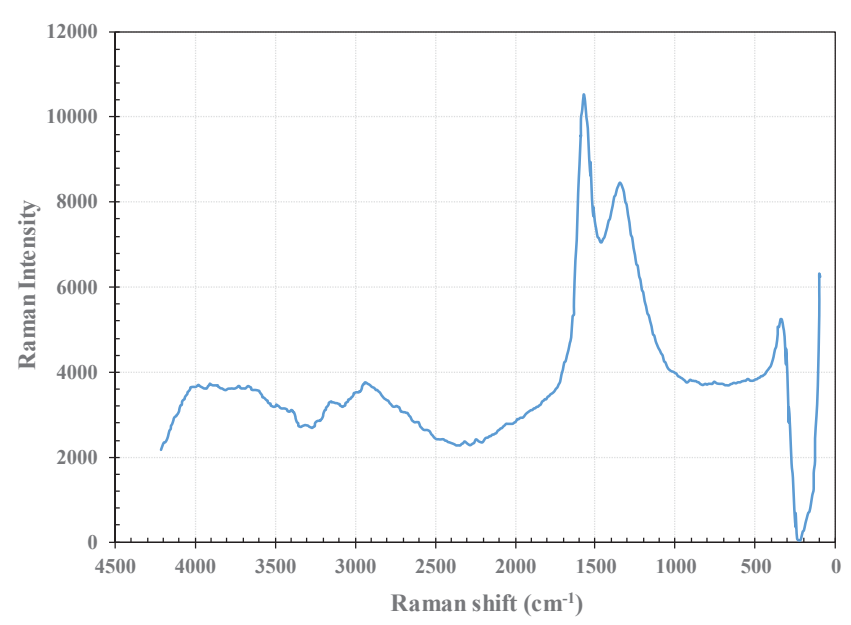

Figure 2

Raman spectra of asphaltene's Soroush oil over the 100$4000 \mathrm{~cm}^{-1}$ range (sample A).

membrane. The light hydrocarbon vapors are collected after condensation in a condenser. The cooling fluid in the condenser is chilled water at a temperature of $5^{\circ} \mathrm{C}$. The experiments were performed at temperatures between 140 and $150{ }^{\circ} \mathrm{C}$. This range is determined as the optimum temperature for separating asphaltene Soroush oil by this set up based on the different examined temperatures from 100 to $160^{\circ} \mathrm{C}$ with $10^{\circ} \mathrm{C}$ increasing step. Nitrogen is purged into the system to prevent a probable explosion of volatile hydrocarbon during heating. It is also used to make required constant feed tank pressure. Nitrogen can also avoid oxidation of the crude oil.

The permeate stream was sampled periodically and weighed to determine the mass flux. During the experiments, temperature and pressure measurements were obtained from thermocouple and pressure gages. The data were collected every five minutes for up to five hours running time. In each hour, the asphaltene content of permeate sample was determined by IP143/01.

\subsection{Raman Experiments}

Asphaltene samples that were collected from membrane output by IP143/01 were categorized into two groups: (a) not including nano particles and (b) in presence of $0.05 \mathrm{wt} \%$ aluminum oxide nanoparticles. For Raman measurements, each sample was milled in a mortar to reduce the particle sizes before being used. The Raman experiments were conducted on an Almega Thermo Nicolet Dispersive Raman Spectrometer equipped with a Charged Coupled Device camera as the detector. The laser wavelength for excitation was $532 \mathrm{~nm}$ and Laser power is $100 \mathrm{~mW}$ but usually, it is used to the power of $30 \mathrm{~mW}$ in order to keep the samples safe. Also, 32 scans measurement were used which took something around $3 \mathrm{~min}$. All spectra were logged in the micro-confocal retro-diffusion configuration for the wave number ranging from 1000 to $1800 \mathrm{~cm}^{-1}$ at room temperature. This range relates to the whole first-order region $\left(1000-1800 \mathrm{~cm}^{-1}\right)$. In order to improve the statistical analysis, several spectra were collected from different points of the flat area.

\subsection{Dynamic Light Scattering (DLS)}

In an attempt to estimate the colloidal asphaltene particle size in the existence and absence of nanoparticles in crude oil matrix, DLS was employed. DLS measurements are performed on a Zetasizer Nano (Malvern Instruments NS) with a scattering angle $\alpha=173$, at a wavelength $\lambda=633 \mathrm{~nm}$. For DLS measurements, around 0.001 gr of solid asphaltene particles were diluted with $5 \mathrm{~mL}$ of toluene, and mixed for $10 \mathrm{~min}$ using ultrasonic, before DLS measurements. Samples were prepared in centrifuge tubes for the sedimentation measurements. DLS analysis was performed at $25^{\circ} \mathrm{C}$. The refractive index of asphaltene in toluene solution was 1.49 .

\section{THEORY}

\subsection{Membrane Separation}

The permeate flux and asphaltene rejection were used to investigate membrane separation performance. In the ultrafiltration process, the true rejection coefficient, $R$, at any time $T$ can be determined from the wall solute concentration, $C_{w}$, and the permeate solute concentration, $C_{p}$, as follows:

$$
R=1-\left(\frac{C_{p}}{C_{w}}\right) \times 100 .
$$

The "permeate mass flux" was calculated by dividing the mass of the permeate sample to the time interval.

\subsection{Theory of Raman}

From the early seventies, Raman spectroscopy has been commonly used for the characterization of carbon-based materials. The overall Raman spectrum from 100 to $4000 \mathrm{~cm}^{-1}$ for asphaltene of Soroush oil is displayed in Figure 2, showing the relative intensity and the position of each Raman bands. Two modes are more important in the Raman spectrum of carbon-based material in the first-order region, $\left(1100-1800 \mathrm{~cm}^{-1}\right)$. The band at $1570 \mathrm{~cm}^{-1}$ is the $\mathrm{G}$ mode corresponding to the movement in the opposite direction of two neighbor carbon atoms in a graphitic sheet. 
This mode in the aromatic hexagonal sheet corresponds to the stretching vibration of the $\mathrm{sp}^{2}$ related to the carbon atom and the chains. Another mode is $1344 \mathrm{~cm}^{-1}$ mode and it is referred to as the D1 mode, commonly called the defect band. For the carbon-based materials, this mode happens particularly when they are spatially poorly organized. However, D1 originates from the heteroatoms and the inplane defects. The Raman spectrum in the $100-4000 \mathrm{~cm}^{-1}$ and $900-1800 \mathrm{~cm}^{-1}$ region are shown in Figures 2 and 3, respectively (Bouhadda et al., 2007).

Since one of the aims of this work is to follow up changing asphaltene's molecule in presence of aluminum oxide nanoparticles, the aggregate structure of asphaltene should be considered. Consequently, microcrystalline planar crystal size $L_{a}$ was determined. $L_{a}$ is obtained by integrated intensities (areas) of the D1 and $\mathrm{G}$ bands $\left(I_{D}\right.$ and $I_{G}$, respectively) (Bouhadda et al., 2007):

$$
L_{a}(n m)=4.4\left(\frac{I_{G}}{I_{D}}\right)
$$

Detailed examination of asphaltene characterization by Raman spectroscopy (Bouhadda et al., 2007) suggested that $\mathrm{G}$ mode peak is much similar to the one seen in commercial carbon black. This similarity does not systematically indicate that molecules are accumulated like a graphite crystal structure but it allows us to use similar analysis, especially about the Tuinstra and Koenig equation as long as the $G$ mode is within the correct range. Since $G$ mode observed is near $1600 \mathrm{~cm}^{-1}$ the Tuinstra and Koenig equation is applicable here (Bouhadda et al., 2007).

\section{RESULTS AND DISCUSSION}

\subsection{Analysis of Raman Data}

Interfacial activity of asphaltene, due to the existence of functional groups in the asphaltene molecule, is so high. Therefore, aluminum oxide nanoparticles were added to facilitate superior asphaltene separation by ultrafiltration. Figure 4 presents the Raman spectrum of asphaltene sample $\mathrm{B}$ (in presence of $0.05 \mathrm{wt} \%$ aluminum oxide nanoparticles). It can be seen that $\mathrm{G}$ mode has been shifted upward slightly to $1575 \mathrm{~cm}^{-1}$, compared to $1570 \mathrm{~cm}^{-1}$. Also, the $1344 \mathrm{~cm}^{-1}$ band corresponded to the $\mathrm{D}$ mode, has been shifted backward to $1336 \mathrm{~cm}^{-1}$. Rigolio et al. discussed that a large aromatic sheet with multiple rings may have a high aromaticity (Rigolio et al., 2001). This itself shows in Raman spectroscopy as a reduction in D1 intensity and a shift of $\mathrm{G}$ band to low frequencies, also it is reported that the position of the $\mathrm{D}$ band and the ratio of $\mathrm{G} / \mathrm{D}$ band intensity alters with covalent modification of the graphite sheet (Bouhadda et al., 2007). Table 2 compares the fitting

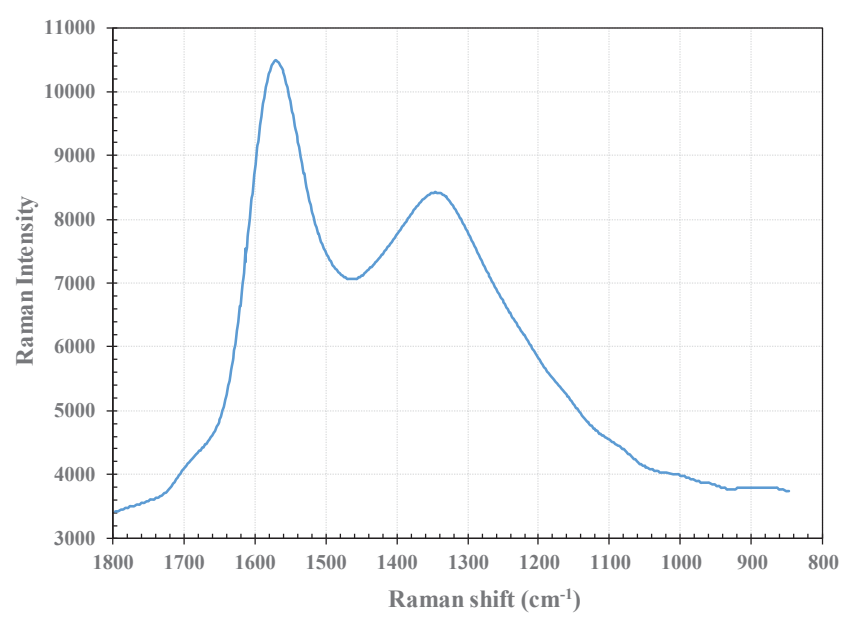

Figure 3

Raman spectra of asphaltene's Soroush oil over the 900 $1800 \mathrm{~cm}^{-1}$ range (sample A).

parameters derived from equation (2) for samples A and B. $L_{a}$ values increase considerably in the presence of nanoalumina because of linking asphaltene particles to nanoalumina particles.

\subsection{Analysis of DLS Data}

DLS results for samples A and B are shown in Figures 5 and 6 . The size of the entities was sensed by DLS, ranging from $90 \mathrm{~nm}$ to $1 \mu \mathrm{m}$. The particle size was measured by the autocorrelation function of the intensity fluctuation of the scattered light. By comparing Figures 5 and 6, it can be realized that there is a significant difference in DLS peaks in presence of nanoparticle, three peaks of asphaltene's molecule were changed to approximately single pick, and also it was shifted in a max boundary of size. According to DLS data, the average of asphaltene molecular size increased from 512.75 to $2949.55 \mathrm{~nm}$ due to the presence of nano aluminum oxide. These results confirmed that asphaltene was linked by aluminum oxide nanoparticle, and hence the molecular sizes were grown up. DLS analysis of asphaltene particles size distribution in terms of intensity in the presence of $0.05 \%$ aluminum oxide is shown in Figure 7. The results showed that in the presence of $0.05 \%$ aluminum oxide nanoparticle, the size of the asphaltene molecule, $4.75 \%$ is higher than the unloaded nanoparticle sample.

\subsection{Effects of Aluminum Oxide Nanoparticles on Membrane Separation}

Experiments were conducted to investigate the effect of the nanoparticles on asphaltene separation of Soroush oil over a range of operating conditions using 


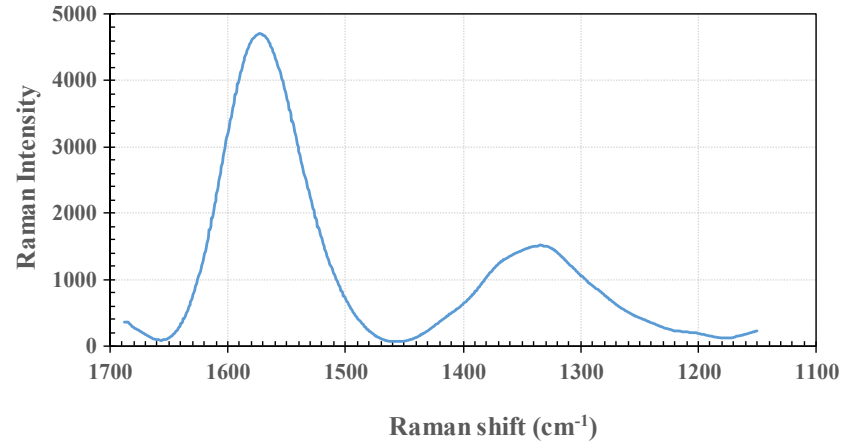

Figure 4

Raman spectra of asphaltene with $0.05 \mathrm{wt} . \%$ aluminum oxide over the $900-1800 \mathrm{~cm}^{-1}$ range (sample B).

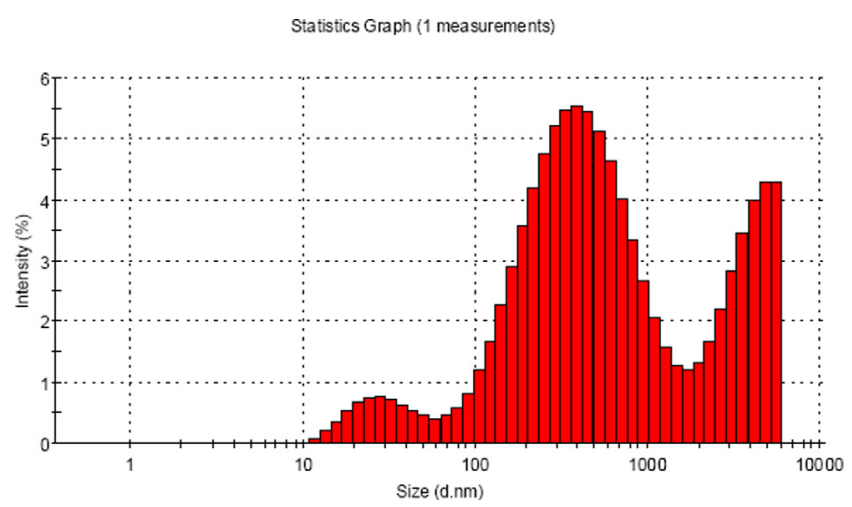

Figure 5

DLS analysis of asphaltene particles size distribution in terms of intensity (sample A).

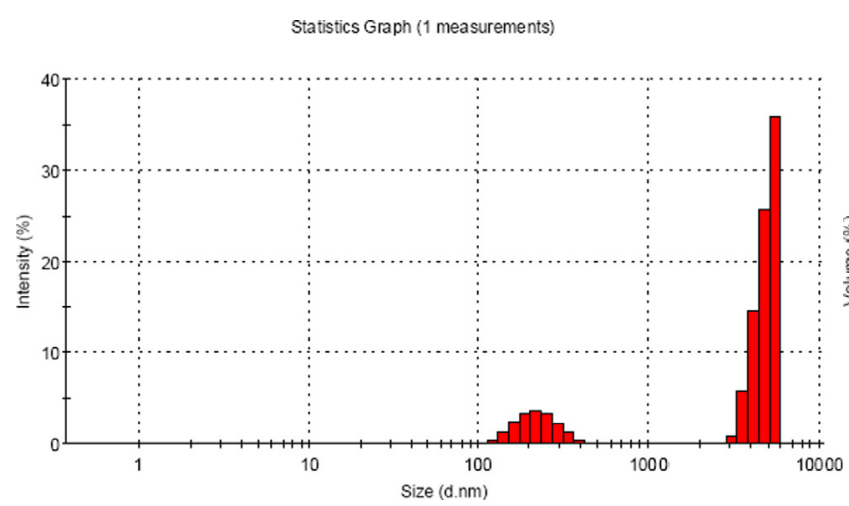

Figure 6

DLS analysis of asphaltene particles size distribution in terms of intensity (sample B).

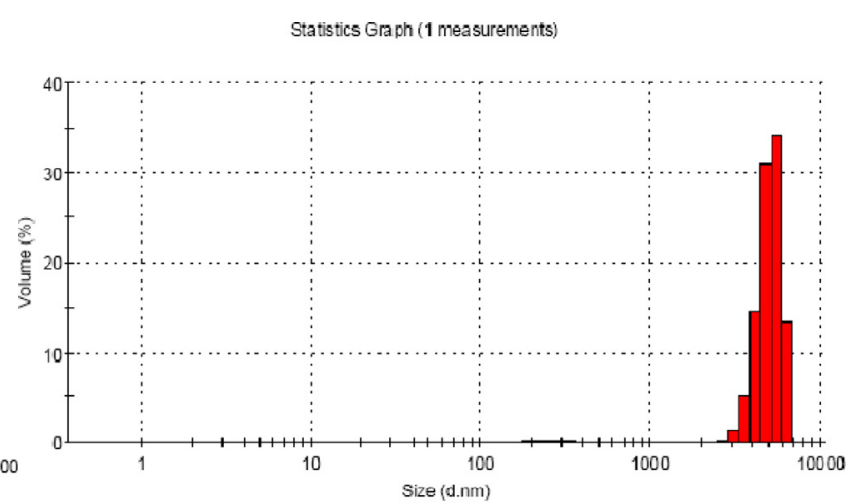

Mean with + -1 Standard Deviation error bar

Figure 7

DLS analysis of asphaltene particles size distribution in terms of intensity in presence of $0.05 \mathrm{wt} . \%$ aluminum oxide.

TABLE 2

Results of the spectral analysis of the Raman spectroscopy on asphaltene samples.

\begin{tabular}{l|l|l|c}
\hline Type of sample & D1 band $\left(\mathrm{cm}^{-1}\right)$ & G band $\left(\mathrm{cm}^{-1}\right)$ & Aromatic sheet diameter $L_{a}(\AA)$ \\
\hline A & 1344 & 1570 & 5.4818 \\
\hline B & 1336 & 1575 & 13.7866 \\
\hline
\end{tabular}

asymmetric ceramic monolith membrane with pore size of $0.2 \mu \mathrm{m}$. Since Soroush oil is extremely viscous $\left(1222 \mathrm{cP}\right.$ at $20^{\circ} \mathrm{C}$; determined by bubble viscometer, according to standard D445-06), the experiments were done at an elevated and optimum temperature (145$\left.150{ }^{\circ} \mathrm{C}\right)$ to reduce viscosity to a suitable level for ultrafiltration. The transmembrane pressure in all experiments was between $300-400 \mathrm{kPa}$. The experiment was continued for about $4 \mathrm{~h}$. The effect of various parameters on filtration characteristics like flux reduction, membrane fouling during constant temperature cross flow UF of Soroush oil was studied.
The results of the asphaltene rejection for samples $\mathrm{A}$ and $\mathrm{B}$ as a function of time during constant temperature are shown in Figure 8. As can be seen, asphaltene rejection is close to $91 \mathrm{wt} . \%$ in the absence of nano alumina and improves to a maximum of about $97 \mathrm{wt} . \%$ if nano alumina is added. This behavior for the UF membrane is as result of linking alumina nanoparticle to the aromatic sheets of asphaltene molecules and growing the size of molecular asphaltene up to $2949.55 \mathrm{~nm}$ according to DLS analysis. On the other hand, asphaltene retention was enhanced by the formation of a cake on the membrane inside surface. 


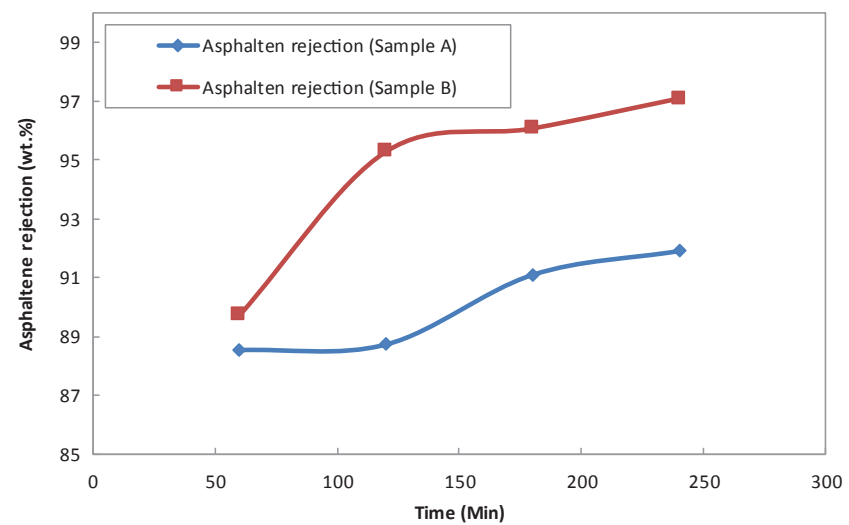

Figure 8

Asphaltene rejection versus time, (sample $\mathrm{A}$ and $\mathrm{B}$, pore size $\left.=0.2 \mu \mathrm{m}, T=140-150^{\circ} \mathrm{C}, \Delta P=300 \mathrm{kPa}\right)$.

Figure 9 compares experimental data for the filtrate flux in terms of time for samples A and B. According to this figure, permeate flux reduces with time as a result of significant fouling in heavy oil UF. Also, there was a steep decline in the flux at the start of the filtration because of initial rapid cake formation on ceramic membrane like other membrane separations. According to previous work (Ashtari et al., 2012) on light and medium Iranian crude oils, a dominant mechanism in asphaltene separation is the formation of a gel layer on the surface of the membrane.

Also, it can be seen from this figure, the permeate flux decreased significantly in presence of nano alumina as a result of growing asphaltene's molecules and developing cake filtration.

\section{CONCLUSION}

The DLS and Raman spectroscopy successfully illustrate the effects of aluminum oxide nanoparticles of Soroush asphaltene during the penetration through the monolith membrane with pore size of $0.2 \mu \mathrm{m}$. Aluminum oxide nanoparticle was applied to alter precipitation and peptization properties of asphaltenes. The asphaltene destabilization was done using crude oil contact with an acid containing dissolved metal ions. The results of Raman spectroscopy showed that the estimated asphaltene molecular sheet dimension, $\left(L_{a}\right)$, was increased dramatically from 5.4818 to $13.7866 \AA$, also according to DLS data, the asphaltene molecular size increased from $512.75 \mathrm{~nm}$ to $2949.55 \mathrm{~nm}$ due to the presence of nano aluminum oxide. Asphaltene rejection, as a result of linking alumina nanoparticles by aromatic sheets in asphaltene molecules and growing the size of molecular asphaltene, was improved significantly. On the other hand, cake on the membrane surface was developed by increasing the molecular size of asphaltene and consequently asphaltene rejection was increased.

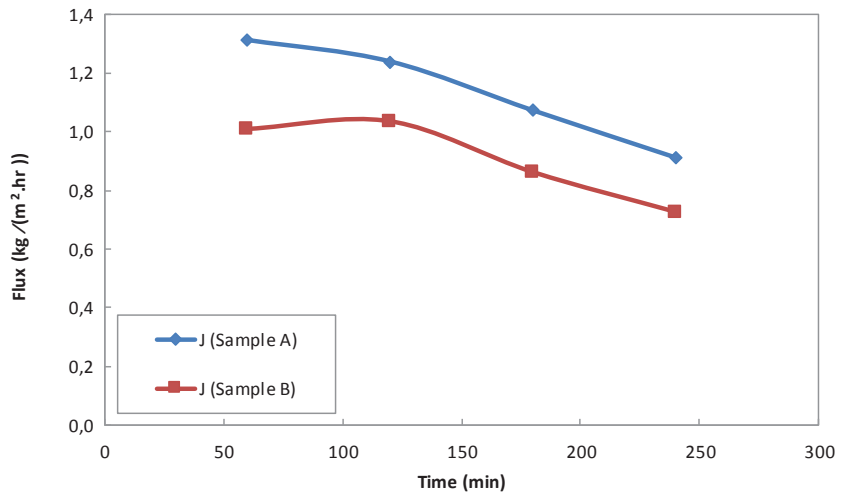

Figure 9

Permeate flux versus time (sample $A$ and $B$, pore size $=0.2 \mu \mathrm{m}$, $\left.T=145-150{ }^{\circ} \mathrm{C}, \Delta P=300 \mathrm{kPa}\right)$.

\section{NOMENCLATURE}

$\begin{array}{ll}\mathrm{UF} & \text { Ultrafiltration } \\ \mathrm{MF} & \text { Microfiltration } \\ T & \text { Temperature }\left({ }^{\circ} \mathrm{C}\right) \\ \Delta P & \text { Transmembrane pressure }(\mathrm{kPa}) \\ \mathrm{D} 1 & \text { Defect band } \\ \mathrm{G} & \text { Graphitic band } \\ I_{D} & \text { Intensities (areas) of the } \mathrm{D} 1 \text { band } \\ I_{G} & \text { Intensities (areas) of the } \mathrm{G} \text { band } \\ L_{a} & \text { Microcrystalline planar crystal size }(\mathrm{nm}) \\ \mathrm{DLS} & \text { Dynamic light scattering } \\ R & \text { Asphaltene rejection }(\mathrm{wt} . \%) \\ J & \text { Permeate flux }\left(\mathrm{kg} / \mathrm{m}^{2} \mathrm{hr}\right) \\ C_{w} & \text { Asphaltene contents in the feed (wt.\%) } \\ C_{p} & \text { Asphaltene contents in the permeate (wt.\%) }\end{array}$

\section{REFERENCES}

Abdrabo A.E., Husein M.M. (2012) Method for converting demetallization products into dispersed metal oxide nanoparticles in heavy oil, Energy Fuels 26, 810-815.

Abu Tarboush B.J., Husein M.M. (2012) Adsorption of asphaltenes from heavy oil onto in situ prepared $\mathrm{NiO}$ nanoparticles, J. Colloid Interface Sci. 378, 64-69.

Ashtari M., Ashrafizadeh S.N., Bayat M. (2012) Asphaltene removal from crude oil by means of ceramic membranes, J. Petrol. Sci. Eng. 82-83, 44-49.

Ashtari M., Carbognani L., Pereira-Almao P. (2016a) Asphaltenes aqueous conversion to humic and fulvic analogs via oxycracking, Energy Fuels 30, 5470-5482.

Ashtari M., Carbognani Ortega L., Lopez-Linares F., Eldood A., Pereira-Almao P. (2016b) New pathways for asphaltenes upgrading using the oxy-cracking process, Energy Fuels 30, 4596-4608.

ASTM (2000) D 6560-00; IP 143/01: Standard Test Method for Determination of Asphaltenes (heptaine Insolubles) in Crude Petroleum and Petroleum Products, American Society for Testing Materials (ASTM). 
Baheri B., Shahverdi M., Rezakazemi M., Motaee E., Mohammadi T. (2015) Performance of PVA/NaA mixed matrix membrane for removal of water from ethylene glycol solutions by pervaporation, Chem. Eng. Commun. 202, 316-321.

Bouhadda Y., Bormann D., Sheu E., Bendedouch D., Krallafa A., Daaou M. (2007) Characterization of Algerian Hassi-Messaoud asphaltene structure using Raman spectrometry and X-ray diffraction, Fuel 86, 1855-1864.

Carlos da Silva Ramos A., Haraguchi L., Notrispe F.R., Loh W., Mohamed R.S. (2001) Interfacial and colloidal behavior of asphaltenes obtained from Brazilian crude oils, J. Petrol. Sci. Eng. 32, 201-216.

Farno E., Rezakazemi M., Mohammadi T., Kasiri N. (2014) Ternary gas permeation through synthesized pdms membranes: Experimental and CFD simulation basedon sorption-dependent system using neural network model, Polym. Eng. Sci. 54, 215-226.

Fasihi M., Shirazian S., Marjani A., Rezakazemi M. (2012) Computational fluid dynamics simulation of transport phenomena in ceramic membranes for $\mathrm{SO}_{2}$ separation, Math. Comput. Model. 56, 278-286.

Goual, L, Sedghi M., Zeng H., Mostowfi F., McFarlane R., Mullins O.C. (2011) On the formation and properties of asphaltene nanoaggregates and clusters by DC-conductivity and centrifugation, Fuel 90, 2480-2490.

Hashemi F., Rowshanzamir S., Rezakazemi M. (2012) CFD simulation of PEM fuel cell performance: Effect of straight and serpentine flow fields, Math. Comput. Model. 55, 1540-1557.

Kaminski T.J., Fogler H.S., Wolf N., Wattana P., Mairal A. (2000) Classification of asphaltenes via fractionation and the effect of heteroatom content on dissolution kinetics, Energy Fuels 14, 25-30.

Marjani A., Rezakazemi M., Shirazian S. (2011) Vapor pressure prediction using group contribution method, Orient. J. Chem. 27, 1331-1335.

Marjani A., Rezakazemi M., Shirazian S. (2012) Simulation of methanol production process and determination of optimum conditions, Orient. J. Chem. 28, 145-151.

Mousavi-Dehghani S.A., Riazi M.R., Vafaie-Sefti M., Mansoori G. A. (2004) An analysis of methods for determination of onsets of asphaltene phase separations, J. Petrol. Sci. Eng. 42, 145156.

Nassar N.N., (2010) Asphaltene adsorption onto alumina nanoparticles: kinetics and thermodynamic studies, Energy Fuels 24, 4116-4122.

Rezakazemi M., Dashti A., Asghari M., Shirazian S. (2017a) $\mathrm{H}_{2-}$ selective mixed matrix membranes modeling using ANFIS, PSO-ANFIS, GA-ANFIS, Int. J. Hydrogen Energy 42, 1521115225.

Rezakazemi M., Ebadi Amooghin A., Montazer-Rahmati M.M., Ismail A.F., Matsuura T. (2014) State-of-the-art membrane based $\mathrm{CO}_{2}$ separation using mixed matrix membranes (MMMs): an overview on current status and future directions, Prog. Polym. Sci. 39, 817-861.

Rezakazemi M., Ghafarinazari A., Shirazian S., Khoshsima A. (2013a) Numerical modeling and optimization of wastewater treatment using porous polymeric membranes, Polym. Eng. Sci. 53, 1272-1278.

Rezakazemi M., Heydari I., Zhang Z. (2017b) Hybrid systems: Combining membrane and absorption technologies leads to more efficient acid gases $\left(\mathrm{CO}_{2}\right.$ and $\left.\mathrm{H}_{2} \mathrm{~S}\right)$ removal from natural gas, J. $\mathrm{CO}_{2}$ Util. 18, 362-369.
Rezakazemi M., Iravaninia M., Shirazian S., Mohammadi T. (2013b) Transient computational fluid dynamics (CFD) modeling of pervaporation separation of aromatic/aliphatic hydrocarbon mixtures using polymer composite membrane, Polym. Eng. Sci. 53, 1494-1501.

Rezakazemi M., Marjani A., Shirazian S. (2013c) Development of a group contribution method based on UNIFAC Groups for the estimation of vapor pressures of pure hydrocarbon compounds, Chem. Eng. Technol. 36, 483-491.

Rezakazemi M., Mohammadi T. (2013) Gas sorption in $\mathrm{H}_{2^{-}}$ selective mixed matrix membranes: Experimental and neural network modeling, Int. J. Hydrogen Energy 38, 14035-14041.

Rezakazemi M., Niazi Z., Mirfendereski M., Shirazian S., Mohammadi T., Pak A. (2011a) CFD simulation of natural gas sweetening in a gas-liquid hollow-fiber membrane contactor, Chem. Eng. J. 168, 1217-1226.

Rezakazemi M., Razavi S., Mohammadi T., Nazari A.G. (2011b) Simulation and determination of optimum conditions of pervaporative dehydration of isopropanol process using synthesized PVA-APTEOS/TEOS nanocomposite membranes by means of expert systems, J. Membr. Sci. 379, 224-232.

Rezakazemi M., Sadrzadeh M., Mohammadi T., Matsuura T. (2017c) Methods for the preparation of organic-inorganic nanocomposite polymer electrolyte membranes for fuel cells, in: Inamuddin, D., Mohammad, A., Asiri, A.M. (eds.), Organic-inorganic composite polymer electrolyte membranes: preparation, properties, and fuel cell applications, Springer International Publishing, Cham, pp. 311-325.

Rezakazemi M., Shahidi K., Mohammadi T. (2012a) Hydrogen separation and purification using crosslinkable PDMS/zeolite A nanoparticles mixed matrix membranes, Int. J. Hydrogen Energy 37, 14576-14589.

Rezakazemi M., Shahidi K., Mohammadi T. (2012b) Sorption properties of hydrogen-selective PDMS/zeolite 4A mixed matrix membrane, Int. J. Hydrogen Energy 37, 17275-17284.

Rezakazemi M., Shahidi K., Mohammadi T. (2015a) Synthetic PDMS composite membranes for pervaporation dehydration of ethanol, Desalin. Water Treat. 54, 1542-1549.

Rezakazemi M., Shahverdi M., Shirazian S., Mohammadi T., Pak A. (2011c) CFD simulation of water removal from water/ ethylene glycol mixtures by pervaporation, Chem. Eng. J. 168, 60-67.

Rezakazemi M., Shirazian S., Ashrafizadeh S.N. (2012c) Simulation of ammonia removal from industrial wastewater streams by means of a hollow-fiber membrane contactor, Desalination 285, 383-392.

Rezakazemi M., Vatani A., Mohammadi T. (2015b) Synergistic interactions between POSS and fumed silica and their effect on the properties of crosslinked PDMS nanocomposite membranes, RSC Adv. 5, 82460-82470.

Rezakazemi M., Vatani A., Mohammadi T. (2016) Synthesis and gas transport properties of crosslinked poly(dimethylsiloxane) nanocomposite membranes using octatrimethylsiloxy POSS nanoparticles, J. Natural Gas Sci. Eng. 30, 10-18.

Rigolio M., Castiglioni C., Zerbi G., Negri F. (2001) Density functional theory prediction of the vibrational spectra of polycyclic aromatic hydrocarbons: effect of molecular symmetry and size on Raman intensities, J. Mol. Struct. 563-564, 79-87.

Rostamizadeh M., Rezakazemi M., Shahidi K., Mohammadi T. (2013) Gas permeation through $\mathrm{H}_{2}$-selective mixed matrix membranes: Experimental and neural network modeling, Int. J. Hydrogen Energy 38, 1128-1135. 
Shahverdi M., Baheri B., Rezakazemi M., Motaee E., Mohammadi T. (2013) Pervaporation study of ethylene glycol dehydration through synthesized (PVA-4A)/polypropylene mixed matrix composite membranes, Polym. Eng. Sci. 53, 1487-1493.

Shirazian S., Marjani A., Rezakazemi M. (2012a) Separation of $\mathrm{CO}_{2}$ by single and mixed aqueous amine solvents in membrane contactors: fluid flow and mass transfer modeling, Eng. Comput. 28, 189-198.

Shirazian S., Pishnamazi M., Rezakazemi M., Nouri A., Jafari M., Noroozi S., Marjani A. (2012b) Implementation of the finite element method for simulation of mass transfer in membrane contactors, Chem. Eng. Technol. 35, 1077-1084.
Shirazian S., Rezakazemi M., Marjani A., Moradi S. (2012c) Hydrodynamics and mass transfer simulation of wastewater treatment in membrane reactors, Desalination 286, 290-295.

Shirazian S., Rezakazemi M., Marjani A., Rafivahid M.S. (2012d) Development of a mass transfer model for simulation of sulfur dioxide removal in ceramic membrane contactors, Asia-Pac. J. Chem. Eng. 7, 828-834.

Vazquez D., Mansoori G.A. (2000) Identification and measurement of petroleum precipitates, J. Petrol. Sci. Eng. 26, 49-55.

Manuscript submitted in 3 February 2017 Manuscript accepted in 12 September 2017 Published online in November 2017 